\title{
DERECHO DE ARBITRAJE ESPAÑOL, ANTONIO MARÍA LORCA NAVARRETE Y JOAQUÍN SILGUEIRO ESTAGNAN
}

\author{
Sergio Peña Neira
}

Antonio María LORCA NAVARRETE y Joaquín SILGUEIRO ESTAGNAN, Derecho de Arbitraje Español (Editorial Dykinson 1994).

Dos profesores de la Escuela de Derecho de la Universidad del País Vasco han seguido una línea de investigación desde hace más de 15 años uno de suyos productos o resultados es el texto Derecho de Arbitraje Español. En efecto en una obra anterior de uno de los autores, el Catedrático Lorca Navarrete, viene a servir de base para la presente, se denomina Arbitraje Interno e Internacional y se editó por Tecnos de Madrid.

El Catedrático Lorca Navarrete ha desarrollado en España y en la Universidad del País Vasco una hasta trayectoria dentro del Derecho procesal y mas específicamente en el Derecho arbitral. Elaboró el reglamento y fundo la Corte Vasca de Arbitraje además de una revista especializada en la materia.

A su vez el profesor Joaquín Silgueiro Estagnan, profesor titular de Derecho procesal en la Universidad del País Vasco desarrolla con singular aplomo y análisis certero, diversos aspectos propios del tema arbitral.

Rigor, erudición y ponderación caracterizan este texto.

Rigor para entregar los elementos de cada etapa del proceso arbitral en su esencia y distinguiendo en un lenguaje cuidado, todos los vericuetos y caminos del arbitraje.

Erudición, ya que se entrega todo lo que han sido las investigaciones y trabajos de años en el tema. Ello implica acotar el objeto de estudio y enriquecerlo con los conocimientos propios de toda la ciencia jurídica, es decir, el estudio del arbitraje y del Derecho procesal.

Ponderación, es una tercera característica del texto. Cada afirmación no se efectúa al azar. Se recurre a una línea de argumentación en que se incorpora tanto la opinión de la doctrina como la de la jurisprudencia y la propia de los autores en torno al tema.

Indudablemente que el principal texto jurídico en estudio es la reciente Ley Española de Arbitraje de 1988 y la misma sirve de excusa para el análisis reemplazando al texto de 1953 criticado por su acento autárquico y territorialis.

Características del texto

Éste contiene un estudio pormenorizado en donde se incluyen formularios, evolución, jurisprudencia, etc. muy apropiados para quienes les corresponda litigar en esta materia. 
A su vez un acabado análisis de las tendencias en el Derecho comparado centrado en la ley inglesa o la norteamericana alcanzan a sus últimas evoluciones. Así también las posiciones que tienen las mismas frente a determinadas materias (vgr. aplicación de laudos) y la adhesión de la ley española a una determinada área u opinión.

El análisis del arbitraje se inicia desde una perspectiva constitucional y de ahí deriva al ámbito legal.

Centran los autores el estudio del arbitraje en las cuestiones litigiosas y, por lo demás, la misma ley de arbitraje así lo regula. En la ley de 1953 se hablaba de arbitraje en el Derecho privado lo que llevaba a tener que determinar el ámbito del Derecho privado y público, con las siguientes dificultades.

\section{Análisis}

Se centra el análisis en el carácter procesal del arbitraje que no implica hablar de jurisdiciconalidad del mismo. Lo que importa es la actividad procesal y garantista del árbitro a través de la técnica procedimental que adopta.

Conjuntamente con lo anterior se concentra el estudio en la actividad que resuelve la cuestión litigioso a través de un "debido proceso sustantivo arbitral" (p.34). Lo anterior deja de lado tanto lo relativo a las teorías juridiccionalistas como privatistas del arbitraje ( En España el Tribunal Constitucional asume la primera teoría p. 34).

Asunto de no poca importancia aparece en el número 27 cuando señala que: "El arbitraje es un ejemplo de una actividad en la que se residencia la sustantividad del proceso a través de la técnica procedimental que se prefiera pero sin que ello suponga en modo alguno una conceptuación jurisdiccional ni del proceso ni del procedimiento arbitral. La resultante es simple: no toda actividad procesal necesariamente ha de ser jurisdiccional, ni toda actividad jurisdiccional ha de ser necesariamente procesal y por tanto sujeta a procedimiento" (p. 36).

Apuntan los autores, lógicamente, las dificultades de determinar cuándo estamos frente a un arbitraje internacional. ( $i$ Es aquel que se lleva adelante en otro estado - el que tiene como partes a personas de diferentes estados o el que se efectúa entre una o ambas partes de origen extranjero pero sobre bienes situados en el país de arbitraje?).

Caso especial es el del arbitraje apátrida en que no se posee un lugar o estado donde se aposentan los actos del procedimiento.

El análisis del arbitraje de Derecho y de equidad se inicia con sus diferencias. Lo esencial es la preexistencia o no de una norma positiva que abstractamente deba ser aplicada en un caso u otro del arbitraje de equidad (p. 54). Se estudia la conveniencia de la opción en favor del arbitraje de equidad (p.58). En dicho análisis se recurre al prof. Sergio La China (U. de Génova) redactor de las normas relativas al procedimiento en el proyecto de Código de la Navegación italiano, substitutivo del de 1942 (p.59). Éste último es obra del maestro italiano Scialojia.

Hay un análisis de las figuras afines al arbitraje y que son equivalentes jurisdiccionales (p.61).

\section{Las ventajas del arbitraje se resumen en :}


simplicidad, b) informalidad, e) especialización, d) rechazo a las soluciones nacionales (especialmente en el arbitraje comercial internacional), e) profesionalismo y $f$ ) conocimiento técnico.

\section{Otros temas de interés}

La ejecución es un tema que abordaremos más adelante. Sin embargo, tomando en consideración la necesidad de una visión global del texto comentado haremos un alcance a los mismos.

Se analiza el convenio arbitral (p. 71), las instituciones de arbitraje (p.131), el objeto (p. 155), los sujetos (p. 239), la intervención jurisdiccional (p. 203), el procedimiento (p. 319), el laudo (p. 401), ejecución (p. 445) y los recursos.

Principios informadores del procedimiento arbitral

La contradicción, la audiencia y la igualdad constituyen el núcleo de estos principios (p.320). Los mismos se consideran garantías constitucionales (p.323) de aquel que accede a la jurisdicción ( $y$, obviamente, al ámbito arbitral ). Dichas garantías, dentro de lo procesal, habrán de ser verificados desde una perspectiva jurisdiccional.

La prueba en el arbitraje

Siempre de interés, el tema de la prueba en el arbitraje asume las ideas de dinamismo, flexibilidad y susceptibilidad para acomodarse a cada instancia del "aquí" y "ahora" (p.385). Entre los principios que rigen esta materia se menciona la libertad formal en el procedimiento probatorio (atípico y no sujeto a procedimiento preclusivo). Se reiteran, a su vez, los principios de audiencia, contradicción y bilateralidad de las partes (p. 387).

La práctica de la prueba, a su vez, aplica el principio de la sustantividad de la misma (en la proposición y en la práctica el tribunal actúa de oficio) convirtiéndose en una excepción al principio tradicional en el proceso civil de disposición por la parte de la ejecución de la rendición de a prueba, sin perjuicio de estar presidida por la oficialidad (p. 388). Los medios no se limitan por un número determinado.

Principios que rigen la Prueba ( $y$ el arbitraje, en general)

No existen, aunque pueda parecer extraño, principios diferentes a los señalados para el Derecho procesal civil, en esta materia. La bilateralidad de la audiencia, la contradictorias y la igualdad son los aspectos sobre los cuales trabaja este procedimiento (p. 28).

\section{La ejecución del laudo}

Por último, aunque no es la parte final del libro, procederemos a reseñar lo relativo a la ejecución del laudo. Ello se aborda en el capítulo X. Se analizan temas de carácter subjetivos (las partes) u objetivos (el laudo y su ejecución) (p. 450).

El reconocimiento del laudo arbitral apátrida aparece como un tema importante., En esta materia se presentan dos tendencias: el pleno reconocimiento limitando el control judicial en esta materia (se sigue en la Arbitration Act inglesa y en la Ley Modelo de la Comisión de Naciones Unidas para el Derecho comercial internacional) o la convergencia del laudo extranjero al nacional (caso español, chileno, francés) ( $p$ 478). 
La verificación y sus causas para el reconocimiento del laudo arbitral extranjero en el Derecho español se trata en la página 481.

En cuanto a una de dichas causas, el Orden Público, no existe un análisis de las diferentes formas que puede alcanzar este concepto, interno, internacional y transnacional ( $\mathrm{Al}$ respecto recomendamos el texto de K-M. Curtin Arbitrating maritime cargo disputes, future problems and consideration en L.M.C.L.Q. 1997 febrero, 46 ss).

En una interesante jurisprudencia del Tribunal Constitucional español se determina el alcance que se da a las excepciones de Orden Público. Ella se puede hacer valer cuando el árbitro extranjero pronuncia su laudo con clara infracción de los Derechos fundamentales (constitucionales) y libertades públicas garantizadas constitucionalmente. El alcance del Orden Público del foro adquiere en este caso un orden estrictamente constitucional (p. 482) (A diferencia de otras reconocimientos efectuados por el Tribunal Supremo español en donde no se explicitaba lo que se entendía por Orden Público). La sentencia que se estudia es del 15 de abril de 1986 . Se incluye a vía de ejemplo en la vulneración de los derechos garantidos por la Constitución el tema de la tutela judicial efectiva y su falta, lo que provoca la indefensión (vgr. la rebeldía en el caso de falta de citación).

Los autores indican que "se fija un concepto de orden público que se identifica con los principios básicos o fundamentales de la organización social y jurídica en los que se inspira el derecho nacional y sólo cuando tales principios se encuentran afectados o vulnerados por la aplicación de una norma extranjera que vaya contra ellos" aparece la necesidad de utilizar la cláusula de Orden Público. Lo anterior siempre con un sentido restrictivo, de conformidad al espíritu que anima en la Convención de Nueva York (p.483).

La limitación y especificación del sentido del concepto de Orden Público (internacional, en este caso) permite utilizar esta forma de solución de conflictos denominada arbitraje no sólo desde una perspectiva interna sino internacional. Ello obviamente, auxilia en el desarrollo del mismo y en la seguridad de los actores comerciales internacionales que tienen en ella una forma clara para alcanzar el termino de sus disputas o el efectivo cumplimiento de las resoluciones que resuelvan las mismas.

Este texto, claramente, no se agota en lo aquí señalado. Vale el poder leerlo y estudiarlo a fin de comprender una institución que ha sufrido modificaciones y desarrollos que son necesario de tener presentes por los operadores jurídicos. 